This is an author produced version of a paper published in European Urology. This paper has been peer-reviewed but does not include the final publisher proof-corrections or journal pagination.

Citation for the published paper:

Höglund, Mattias.

"On the Origin of Syn- and Metachronous Urothelial Carcinomas"

European Urology, 2006, Issue: Nov 16.

http://dx.doi.org/10.1016/j.eururo.2006.11.025

Access to the published version may require journal subscription.

Published with permission from: Elsevier 


\title{
On the origin of syn- and metachronous urothelial carcinomas
}

\author{
Mattias Höglund
}

Department of Clinical Genetics , Lund University Hospital, Lund SE-221 85 Sweden.

Tel.: +46 46 173739, Fax: +46 46 131061. E-mail: mattias.hoglund@med.lu.se

Key words: urothelial carcinoma, metachronous tumors, intra epithelial migration, field cancerization, tumor recurrence, genetic changes.

Word count: 3994

Take home message: An alternative model for the origin of syn- and metachronous tumors that better explain the existing genetic data is described. 


\section{Abstract}

Objective: To evaluate existing models for the origin of meta- and synchronous urothelial carcinomas in light of the accumulated genetic data.

Methods: Published studies on the clonal origin and genetic relationships of syn- and metachronous tumors, genetic aberrations in normal and premalignant urothelial lesions, as well as histological and genetic mapping studies of cystectomized bladder samples are reviewed.

Results: The most common models for the origin of syn- and metachronous tumors are found to conform less well to the accumulated genetic data. A new model is proposed, the field-firsttumor-later model, in which aberrant cells with a stem cell, or stem cell like, origin spread in the urothelium by cellular displacement creating fields of premalignant cells. Tumor growth is suggested to be initiated by critical genetic events occurring in individual cells in such fields. Hence, recurring tumors is proposed to originate from a shared field of premalignant cells and not from previous overt tumors.

Conclusion: The proposed model can better account for the existing genetic and histological data on syn- and metachronous urothelial carcinomas. 


\section{Introduction}

Urothelial carcinomas (UC) originate from the epithelial cells of the inner lining of the bladder wall. The majority of the tumors is papillary and confined to the urothelial mucosa (stage $\mathrm{Ta}$ ) or to the lamina propria (stage $\mathrm{T} 1$ ) whereas the remaining are muscle invasive (T2T4). Most Ta tumors are of low grade (G1 or G2), rarely progress, and are associated with a favorable prognosis whereas high grade $\mathrm{Ta}(\mathrm{TaG} 3)$ and $\mathrm{T} 1$ tumors represent a significant risk of tumor progression. Carcinoma in situ, Tis, is a flat lesion commonly found in association with malignant tumors and is generally believed to be the precursor of invasive cancer. Patients with Ta and T1 tumors are typically treated by transurethral resection, often combined with intravesical chemo- or immunotherapy. However, up to $70 \%$ of the patients show recurrences after treatment making a lifelong follow-up by regular cystoscopy necessary. This growth pattern of UC gives an opportunity to investigate the early stages of tumor development as both recurrences and multiple tumors from the same patients frequently are available. Particularly, "re-initiation” of the transforming process in the same genetic and environmental background may be studied. Furthermore, the topology of the bladder organ has made it possible to analyze non-cancerous tissue in patients with UC in a systematic way. In the present review the data on genetic changes in normal, premalignant, as well as in synchronous and metachronous UC tumors will be examined. Suggested hypotheses for the origin of synchronous and metachronous tumors will be evaluated in view of the existing data and possible alternative explanations will be put forward.

\section{Syn- and metachronous tumors are clonally related.}

Three major hypotheses have been proposed to explain both the origin of multiple and of recurring tumors; field cancerization [1], seeding [2], and intra epithelial migration [3]. The field-cancerization model assumes that the urothelium is exposed to mutational stress, due to e.g., waist products collected in the urine, and that accumulation of mutations in individual cells eventually will lead the initiation of a cancer process. In this model tumors are caused by independent events and will consequently have different cellular origins and be non-clonal. The idea behind intraluminal seeding is that recurrent and multiple tumors arise from the shredding of cells from a primary tumor and that shred cells are re-implanted in the normal mucosa in which they initiate the growth of a new tumor. As the syn- or metachronous tumors in this scenario will originate from a primary tumor, the resulting tumors will be clonally related. In the intra epithelial migration model tumor cells are believed to spread through the normal mucosa by migration. The resulting tumors will be clonal as they originate from the 
same primary tumor. In addition, if intra epithelial migration occurs one is expected to find tumor cells located in the normal urothelium between tumor foci.

As one of the major questions regarding syn- or metachronous tumors is their clonal relationship, this has been the topic for many investigations. A factor complicating the interpretations of the published results is that the term clonality is not always used with the same meaning and that different molecular tools used to establish clonality does not always measure the same thing. Clonality could mean that tumor B has originated from cells in tumor A, however, it could also mean that cells in tumors A and B share the same cellular origin but has not evolved from each other. In the first situation genetic changes present in tumor $\mathrm{A}$ is expected to be present also in tumor B, as B represents a development of cells in tumor A. In Figure 1 tumor B may have originated from tumor A as B has both a HRAS and a TP53 mutation. However, tumor $\mathrm{C}$ would have had a different origin. The most common meaning of clonal relationship is however that tumors share the same progenitor cell. As progenitor cells may give rise to many daughter cells and these daughter cells may accumulate different mutations, tumors with a common progenitor may not necessarily share a common mutation profile. Hence, tumors A, B, and C in Figure 1 may very well be clonal even though tumor C does not show HRAS and TP53 mutations and tumors A and B does not show FGFR3 mutations; the tumors may simply represent different developmental endpoints. Furthermore, the interpretation of the results is highly dependent of the type of markers used to establish clonality. If the applied genetic marker represent a late event in tumor development such as e.g., mutations in the TP53 gene, similar mutation patterns would indicate clonality but different patterns would not prove oligoclonality. Hence, if the aim is to trace the origin to a common progenitor cell a genetic change that occurs early in tumor development is favorable, and a genetic marker that is established before the initiation of this process would be even more informative. A marker of the latter kind is X-chromosome inactivation patterns. Females have two X-chromosomes in all of their cells but only one of them is active. One of the Xchromosomes is always maintained in an inactive state through DNA modification by methylation. X-chromosome inactivation occurs early in development and is a random event. However, once a chromosome is inactivated all its descendants' remains inactivated; hence, all related daughter cells show inactivation of the same X-chromosome. If an individual is polymorphic for an X-linked marker and it is possible to establish which allele (gene variant) that is methylated, it is possible to determine if two cells show inactivation of the same $\mathrm{X}$ chromosome or not. Importantly though, X-chromosome inactivation analyses can only disprove mono-clonality, not prove it, as two different cell clones may have inactivated the 
same X-chromosome by chance. The most commonly used gene for these purposes is the human androgen receptor gene, $A R$; if syn- or metachronous tumors share a common progenitor cell they are also expected to show inactivation of the same $A R$ allele. Thus if tumors A, B, and C in Figure 1 show inactivation of the same X chromosome, as indicated, they are likely to be clonal even though they do not share all late genetic changes. Sidransky et al. [4] and Li et al. [5] used X-inactivation studies to establish the clonal relationship among syn- and metachronous tumors from a total of 23 patients. In each case the tumors from the same patient did show X-inactivating patterns consistent with a monoclonal origin. Other investigators have used loss of heterozygosity analysis ( $\mathrm{LOH})$, that determine the loss of specific gene alleles, chromosomal analysis using fluorescent in situ hybridization (FISH), or gene mutation analyses to perform similar investigations e.g., Simon et al. [6] showed that 32 tumors from six patients showed patterns signifying monoclonality. In some investigations it has not been possible to establish clonal relationship of syn- or metachronous tumors in all patients [2,7,8,9]. However, as $\mathrm{LOH}$ analysis was used in these investigations and $\mathrm{LOH}$ events may occur late in tumor development, these findings do not exclude a clonal relationship among the differing tumors. Irrespective if these latter cases represent examples of true oligoclonality or not, the major part of investigated tumors from the same patients does show molecular patterns consistent with having a monoclonal origin. Hence, it may be concluded that the vast majority of syn- and metachronous tumors show a clonal relationship and that the model of field-cancerization is not an appropriate explanation for tumor recurrence and multiple tumors.

\section{Premalignant lesions and morphologically normal urothelium in patients with urothelial carcinoma show genetic changes.}

Almost all human malignancies are characterized by having chromosomal changes. Furthermore, there is a correlation between the numbers of chromosomal changes and the aggressiveness of the cancer. Chromosomal changes believed to occur early in UC development and thus prevalent in low grade and low stage tumors are loss of chromosome 9 and gain of the long arm of chromosome 1 whereas chromosomal changes believed to occur late in tumor development include loss of the short arms of chromosomes 3, 4, and 8, and the long arm of chromosome 5 [10]. There is growing evidence that chromosomal changes characteristic of UC are already present in premalignant lesions such as hyperplasia and dysplasia. Hartmann et al. [11] demonstrated that hyperplasias showed monosomies or partial losses of chromosome 9 and that the same genetic alterations were seen in the concomitant 
papillary tumors. In addition, in two out of six investigated patients, chromosome 9 deletions were also detected in the normal epithelium adjacent to the tumor. Oberman et al. [12] showed by comparative genome hybridization (CGH), which identifies patterns of chromosomal gains and losses, and LOH analyses that flat urothelial hyperplasias showed chromosomal changes shared by concomitant papillary tumors. Chow et al. [13] also used CGH to show that hyperplasias shared changes with the concomitant papillary tumors. These findings were verified by FISH that also detected losses of chromosome 9 in normal epithelium. Furthermore, dysplasias show chromosomal and genetic changes highly similar to what is seen in cancer in situ [14]. Hence, it may be concluded that precancerous lesions show the same genetic alterations as overt cancers.

As noted, the presence of cancer related mutations is not limited to precancerous lesions but is also seen in morphologically normal urothelium in patients with UC. Cianciulli et al. [15] showed by FISH analyses that morphologically normal urothelium from patients with UC demonstrated genetic aberrations common to those of bladder cancer. Particularly loss of chromosome 9 and gain of chromosome 7 was seen in the tumors, the proximal, and the distal mucosa. Steidl et al. [16] showed by FISH analyzes that tumors and their adjacent normal urothelium were affected by similar chromosomal aberrations. Genomic imbalances in normal urotheliun have also repeatedly been shown by CGH and LOH $[17,18,19]$ e.g., Stoehr et al. [20] found $\mathrm{LOH}$ of chromosomes 9 and 8 in histologically normal epithelium in five out of fifteen patients. Thirty cases with no history of UC were used as controls and no LOH was found. This shows that the normal urothelium in patients with UC is different from normal urothelium from individuals with no signs of UC. The genetic alterations seen in normal and premalignant cells are not limited to chromosomal changes but also include gene mutations and epigenetic changes $[6,18,21]$ e.g., normal urothelium, preneoplastic lesions, as well as tumors from the same patient may share the same TP53 mutation [22]. As a prerequisite to detect chromosomal changes by $\mathrm{LOH}$ and by $\mathrm{CGH}$, and gene mutations by DNA sequencing is that a large proportion if the investigated material share the same changes, substantial proportions, and not just occasional cells, of the normal tissue show genetic alterations. Hence, genetically aberrant but morphologically non-cancerous cells appear to surround the growth of carcinomas at high densities.

Histologic and genetic mapping studies represent a more thorough approach to study the urothelium in patients with UC. In these studies the complete surface of a cystectomized bladder is divided into a large number of sections organized into a coordinate system. Each section is then evaluated both by histopathological and by genetical means ultimately creating 
a detailed map of the bladder surface. The first histololgic/genetic map of this kind was reported by Chaturvedi et al. [23] that analyzed aberrations of chromosome 17 using $\mathrm{LOH}$ and mutations in TP53 by sequencing. By superimposing the $\mathrm{LOH}$ data with histological data two patterns were seen; a scattered pattern with several isolated regions showing $\mathrm{LOH}$ for specific markers and a plaque like pattern consisting of a continuous areas showing $\mathrm{LOH}$ for the same marker. Some of the plaque like alterations involved large areas of bladder mucosa encompassing various histological precursor lesions and areas of morphologically normal urothelium. LOH of chromosome 17 was seen in the invasive and in the preinvasive phases of the urothelial neoplasia, as well as in the microscopically normal urothelium. This indicates that $\mathrm{LOH}$ of chromosome 17, associated with invasive tumors, preceded the development of morphologically recognizable changes. Similar distributions of genetic changes and histological subtypes have also been shown for chromosome 9 and CDKN2A (p16) [24] and for chromosome 13 and RB1 mutations [25]. In a similar analysis Stoehr et al. [26] showed that TP53 mutations were detected in regions with preneoplastic lesions as well as in normal urothelium and Simon et al. [6] showed that synchronous tumors with TP53 mutations were located within continuous areas of normal urotheliun with TP53 mutations, whereas tumors with a normal TP53 gene were located within areas of urothelium showing no mutations. Genetic and histologic mapping has also shown that LOH for chromosomes 4, 8, 9, 11, and 17 may be detected in the normal urothelium demonstrating that extensive karyotypic evolution may occur already in morphologically normal cells [27].

Histologic and genetic mapping of bladders with UC have thus shown that areas with $\mathrm{LOH}$ and gene mutations may cover large parts of the urothelium. This indicates that a massive intraepithelial spread of genetically altered cells has taken place. Some markers showed $\mathrm{LOH}$ in almost all of the mapped segments, indicating large clonal segments, whereas others were scattered and showed "islands" of LOH. This shows that the cells evolve locally during spreading, resulting in a genetically heterogeneous field of cells. The TP53 mutation mapping of cystectomized bladders demonstrates further that tumors are located in fields of normal/preneoplastic cells showing the same gene mutation as in the tumor proper. Hence, even though intraluminal seeding may occur, the accumulated histological-genetic mapping data favors intraepithelial migration as the most prominent mechanism for tumor spread and recurrence. 


\section{The chronology of tumor appearance does not coincide with the genetic evolution of tumors cells.}

As mentioned, tumors evolve by the accumulation of genetic changes. Many of these changes are irreversible or are very unlikely to revert by chance. For instance, loss of heterozygosity $(\mathrm{LOH})$ means that one of two gene variants, or alleles, present in the original cell is lost during tumor development. Even though the cell may duplicate the remaining gene allele and thus regain two gene copies, these two gene copies will now be identical; the lost gene variant cannot be regained. Thus by establishing the genetic changes in a series of tumors e.g., from the same patient, it would be possible to determine a genetic order of the samples. If recurrences originate from the tumors previously resected and several recurrences are sampled from the same patient it would be expected that the genetic order of the tumors determined by the acquired genetic changes would coincide with the chronology of tumor presentation. This is however not the case. van Tilborg et al. [28] studied 11 patients with five or more recurrences using $\mathrm{LOH}$ and mutation analyses. For each patient a chronology of the recurrences based on genetic events was established. However, no correlation was found between the genetic chronology and the chronology of tumor appearance; recurrences with many chromosomal changes could appear long before clonally related recurrences with few chromosomal changes. These findings have been corroborated in a recent study using CGH, $\mathrm{LOH}$, and mutations analysis [Lindgren et al. personal communication]. This suggests that the recurring tumor could not have evolved directly from the previous tumor. It also suggests that the cells resulting in late recurrences with few genetic changes would have been present in the urothelium at the time when the early and more genetically evolved recurrence was resected. The suggested lack of correlation between the chronological appearance of tumors and genetic progression is also supported by the fact that recurring tumors may be of lower grade than the preceding ones [29] and that TP53 and FGFR3 mutations present in a primary tumor may be absent in recurrent tumors [30, Lindgren et al. personal communication ]. These findings suggests that cells or segments of the urothelium with differently evolved but clonally related genomes may co-exist and produce overt tumors independently, and are at odds with the suggestion that recurrences and multiple tumors originate by intraepithelial migration of cells from a preceding tumor. 


\section{An alternative view $o$ the origin of syn- and metachronous tumors.}

The data favoring the presence of genetic changes characteristic of carcinomas in morphologically normal urothelium, including $\mathrm{LOH}$, chromosomal changes, and gene mutations, is extensive. The detailed histologic-genetic mapping shows that regions with shared genetic aberrations can in fact cover a large part of the bladder urothelium. Furthermore, islands of cells containing additional genetic markers indicate local genomic divergence and hence that affected fields may be genetically heterogeneous. The affected regions are also characterized by morphological heterogeneity in that they demonstrate several different preneoplastic and neoplastic lesions. The emerging picture is thus that urothelial carcinomas are located within continuous fields of genetically and histologically aberrant cells. There remain two major alternative explanations for the source of such fields, the commonly suggested intraepithelial migration of cancer cells, the tumor-first-field-later model, and the recently suggested alternative field-first-tumor-later model [31] in which nonmalignant but genetically modified cells spread though the epithelium and eventually develop to frank tumors. In case of intraepithelial migration one has to explain a switch from an adherent to a migrating phenotype. As most primary and recurrent Ta tumors are of low grade and thus exhibit epithelial or epithelial like characteristics, including being less inclined to migrate, the primary tumor cells has to pass through an epithelial-mesenchymal transition (EMT) to facilitate migration [32]. After migration the tumor cells are expected to initiate a second tumor, again showing epithelial like characteristics, a change that would include a reversal of the previous transition, i.e., a mesenchymal-epithelial transition. These cellular transitions are complex and involve several genetic regulatory systems that have to be turned on and off in a reversible and coordinated way [32]. Furthermore, migrating tumor cells have to stay dormant for an extended period of time as recurrences may appear some years after resection of the primary tumor. Taken together, the complex changes that is assumed to occur in a migration model together with the finding that the chronology of tumor appearance does not adhere to the chronology of the genetic evolution, makes the tumor-first-field-later model less likely.

An alterative explanation could involve expanding clones of aberrant stem cells, or self renewing cells. The existence of cancer stem cells has been reported for several malignancies $[33,34,35]$ and they are believed to play a major role in the development and behavior of these cancer types. Self-renewing cancer cells may either derive from stem cells, restricted progenitor cells, or from differentiated cells that acquire a self-renewal potential. In light of this suggestion one may ask if there is any support for the existence of urothelial stem cells. 
Indeed, Tsai et al. [36] showed by $\mathrm{X}$ chromosome inactivation analysis of cells microdissected from normal female human bladders that the urothelium is organized in patches of monoclonal cells about $120 \mathrm{~mm}^{2}$ in size. The patches were estimated to contain approximately $2 \times 10^{6}$ cells and the authors suggested that they were composed of descendants of an original founder cell, a stem cell, and estimated the number of such cells to 200-300 per bladder. This suggests that the bladder mucosa is organized into a large number of segments responsible for maintaining the integrity of the urothelial cell layer and that these segments to some extent may behave independently.

A possible scenario could thus be that a self-renewing cell acquires genetic alterations that partly blocks differentiation, and then colonizes the patches described by Tsai et al. [36]. All cells in a patch would in this scenario eventually become genetically altered daughter cells. As a result of subsequent genetic alterations successive cells may escape normal growth control by neighboring cells and develop into expanding clones that invade adjacent patches and laterally displace the normal epithelium resulting in fields of premalignant cells [37]. Thus the spreading of premalignant cells would involve intraurothelial displacement, rather than intra epithelial migration, replacing the genetically normal epithelium. The outcome of this process would be a field of clonally related epithelial cells with cancer-associated genetic alterations, but without invasive or exophytic growth making it a histopathologically benign lesion. The process of multistep carcinogenesis is most likely operating already during field extension as several chromosomal changes and gene mutations has been shown to be present in morphologically normal urothelium in patients with UC. In addition, in the few cases where microarray analyses have been performed on both tumors and on the adjacent normal looking urothelium, the normal urothelium show the same expression patterns as the overt tumor $[38,39]$. As a consequence of accumulated genetic changes, individual cells will eventually develop into frank carcinomas, the field-first-tumor-later model (Figure 2). At the time of tumor presentation the urothelium most likely already is in a state of criticality showing several genetically evolved and divergent segments. It could be envisaged that a transforming event, e.g., a profound increase in proliferation, in an individual cell in such a field may result in a local cancerous growth but leaving the neighboring cells in their respective states. In this scenario bladder cancer would not be a local disease but "a local manifestation of a diffuse abnormality of the urothelium” [40]. This scenario could also explain why the chronology of tumor presentation rarely coincides with the chronology of the genetic evolution; the triggering events causing the final transformation may occur independently and in differentially evolved sub-sections of the urothelium. Most probably these fields expand over 
a period of time, creating no or only mild symptoms. In light of this, the expanding field of preneoplastic cells may be compared to a chronic phase and the local transitions to cancerous growth to an acute phase, in analogy with the transition of chronic myeloid leukemia (CML) to acute myeloid leukemia (AML). The chronic phase would include the induction of selfrenewal capacity and ultimately in a field-defect, and the acute phase a local transformation of preneoplastic cells to overt tumors. In this scenario the frequency by which recurrences occur would be dependent on both the size as well as the genetic heterogeneity [41] of the affected fields and not strictly on the genetic changes in the preceding tumors.

\section{Conclusions}

One of the key challenges in the management of UC is the high frequency of recurrences. Some success in prolonging the recurrence free period after TUR have been accomplished by combining TUR with intravesical chemo- or immunotherapy. Still, even if adjuvant treatment, directed towards fully transformed cells, will eradicate any remaining tumor cells due to shredding, insufficient resection, or remaining microscopic tumors not seen by conventional cystoscopy, the major source for recurrences will remain; an urothelium in a state of criticality that locally may transform into an overt tumor. An alternative treatment would be to target genetic changes present in cells constituting the affected fields with chemotherapeutic agents. If, however, the field-defect is a consequence of the activity of cancer stem cells, cancer stem cells should be the ultimate target for therapy. Thus a major future goal in the analysis of UC is to identify and characterize possible bladder cancer stem cells.

\section{References}

[1] Slaughter DP, Southwick HW, Smejkal W. Field cancerization in oral stratified squamous epithelium; clinical implications of multicentric origin. Cancer 1953;6:963968.

[2] Hafner C, Knuechel R, Zanardo L, Dietmaier W, Blaszyk H, Cheville J, Hofstaedter F, Hartmann A. Evidence for oligoclonality and tumor spread by intraluminal seeding in multifocal urothelial carcinomas of the upper and lower urinary tract. Oncogene 2001;20:4910-4915. 
[3] Hafner C, Knuechel R, Stoehr R, Hartmann A. Clonality of multifocal urothelial carcinomas: 10 years of molecular genetic studies. Int J Cancer. 2002 Sep 1;101(1):1-6.

[4] Sidransky D, Frost P, Von Eschenbach A, Oyasu R, Preisinger AC, Vogelstein B. Clonal origin bladder cancer. N Engl J Med 1992;326:737-740.

[5] Li M, Cannizzaro LA. Identical clonal origin of synchronous and metachronous lowgrade, noninvasive papillary transitional cell carcinomas of the urinary tract. Hum Pathol 1999;30:1197-1200.

[6] Simon R, Eltze E, Schafer KL, Burger H, Semjonow A, Hertle L, Dockhorn-Dworniczak B, Terpe HJ, Bocker W. Cytogenetic analysis of multifocal bladder cancer supports a monoclonal origin and intraepithelial spread of tumor cells. Cancer Res 2001;61:355-32.

[7] Hartmann A, Rösner U, Schlake G, Dietmaier W, Zaak D, Hofstaedter F, Knuechel R.. Clonality and genetic divergence in multifocal low-grade superficial urothelial carcinoma as determined by chromosome 9 and p53 deletion analysis. Lab Invest 2000;80:709-718.

[8] Takahashi T, Habuchi T, Kakehi Y, Mitsumori K, Akao T, Terachi T, Yoshida O. Clonal and chronological genetic analysis of multifocal cancers of the bladder and upper urinary tract. Cancer Res 1998;58:5835-5841.

[9] Cheng L, Gu J, Ulbright TM, MacLennan GT, Sweeney CJ, Zhang S, Sanchez K, Koch MO, Eble JN. Precise microdissection of human bladder carcinomas reveals divergent tumor subclones in the same tumor. Cancer 2002;94:104-110.

[10] Höglund M, Säll T, Heim S, Mitelman F, Mandahl N, Fadl-Elmula I. Identification of cytogenetic subgroups and karyotypic pathways in transitional cell carcinoma. Cancer Res 2001 Nov 15;61(22):8241-6.

[11] Hartmann A, Moser K, Kriegmair M, Hofstetter A, Hofstaedter F, Knuechel R. Frequent genetic alterations in simple urothelial hyperplasias of the bladder in patients with papillary urothelial carcinoma. Am J Pathol 1999;154:721-7. 
[12] Obermann EC, Junker K, Stoehr R, Dietmaier W, Zaak D, Schubert J, Hofstaedter F, Knuechel R, Hartmann A. Frequent genetic alterations in flat urothelial hyperplasias and concomitant papillary bladder cancer as detected by CGH, LOH, and FISH analyses. J Pathol 2003;199:50-7.

[13] Chow NH, Cairns P, Eisenberger CF, Schoenberg MP, Taylor DC, Epstein JI, Sidransky D. Papillary urothelial hyperplasia is a clonal precursor to papillary transitional cell bladder cancer. Int J Cancer. 2000;89:514-518.

[14] Hartmann A, Schlake G, Zaak D, Hungerhuber E, Hofstetter A, Hofstaedter F, Knuechel R. Occurrence of chromosome 9 and p53 alterations in multifocal dysplasia and carcinoma in situ of human urinary bladder. Cancer Res 2002;62:809-818.

[15] Cianciulli AM, Leonardo C, Guadagni F, Marzano R, Iori F, De Nunzio C, Franco G, Merola R, Laurenti C. Genetic instability in superficial bladder cancer and adjacent mucosa: an interphase cytogenetic study. Hum Pathol 2003;34:214-221.

[16] Steidl C, Simon R, Burger H, Brinkschmidt C, Hertle L, Bocker W, Terpe HJ.Patterns of chromosomal aberrations in urinary bladder tumours and adjacent urothelium. J Pathol 2002;198:115-120.

[17] Baud E, Catilina P, Boiteux JP, Bignon YJ. Human bladder cancers and normal bladder mucosa present the same hot spot of heterozygous chromosome-9 deletion. Int J Cancer 1998;77:82182-4.

[18] Muto S, Horie S, Takahashi S, Tomita K, Kitamura T. Genetic and epigenetic alterations in normal bladder epithelium in patients with metachronous bladder cancer. Cancer Res 2000;60:4021-4025.

[19] Junker K, Boerner D, Schulze W, Utting M, Schubert J, Werner W. Analysis of genetic alterations in normal bladder urothelium. Urology 2003;62:1134-1138. 
[20] Stoehr R, Zietz S, Burger M, Filbeck T, Denzinger S, Obermann EC, Hammerschmied C, Wieland WF, Knuechel R, Hartmann A. Deletions of chromosomes 9 and 8p in histologically normal urothelium of patients with bladder cancer. Eur Urol 2005;47:5863.

[21] Pycha A, Mian C, Hofbauer J, Brossner C, Haitel A, Wiener H, Marberger M. Multifocality of transitional cell carcinoma results from genetic instability of entire transitional epithelium. Urology. 1999;53:92-97.

[22] Stoehr R, Knuechel R, Boecker J, Blaszyk H, Schmitt R, Filbeck T, Hofstaedter F, Hartmann A. Histologic-genetic mapping by allele-specific PCR reveals intraurothelial spread of p53 mutant tumor clones. Lab Invest 2002;82:1553-61.

[23] Chaturvedi V, Li L, Hodges S, Johnston D, Ro JY, Logothetis C, von Eschenbach AC, Batsakis JG, Czerniak B. Superimposed histologic and genetic mapping of chromosome 17 alterations in human urinary bladder neoplasia. Oncogene 1997;14:2059-2070.

[24] Czerniak B, Chaturvedi V, Li L, Hodges S, Johnston D, Roy JY, Luthra R, Logothetis C, Von Eschenbach AC, Grossman HB, Benedict WF, Batsakis JG. Superimposed histologic and genetic mapping of chromosome 9 in progression of human urinary bladder neoplasia: implications for a genetic model of multistep urothelial carcinogenesis and early detection of urinary bladder cancer. Oncogene 1999;18:118596.

[25] Kim MS, Jeong J, Majewski T, Kram A, Yoon DS, Zhang RD, Li JZ, Ptaszynski K, Kuang TC, Zhou JH, Sathyanarayana UG, Tuziak T, Johnston DA, Grossman HB, Gazdar AF, Scherer SE, Benedict WF, Czerniak B. Evidence for alternative candidate genes near RB1 involved in clonal expansion of in situ urothelial neoplasia. Lab Invest. 2006 Feb;86(2):175-90.

[26] Stoehr R, Knuechel R, Boecker J, Blaszyk H, Schmitt R, Filbeck T, Hofstaedter F, Hartmann A. Histologic-genetic mapping by allele-specific PCR reveals intraurothelial spread of p53 mutant tumor clones. Lab Invest 2002;82:1553-61. 
[27] Czerniak B, Li L, Chaturvedi V, Ro JY, Johnston DA, Hodges S, Benedict WF. Genetic modeling of human urinary bladder carcinogenesis. Genes Chromosomes Cancer 2000;27:392-402.

[28] van Tilborg AA, de Vries A, de Bont M, Groenfeld LE, van der Kwast TH, Zwarthoff EC. Molecular evolution of multiple recurrent cancers of the bladder. Hum Mol Genet. 2000;9:2973-2980.

[29] Borhan A, Reeder JE, O'Connell MJ, Wright KO, Wheeless LL, di Sant'Agnese PA, McNally ML, Messing EM. Grade progression and regression in recurrent urothelial cancer. J Urol 2003;169:2106-9.

[30] Dahse R, Gartner D, Werner W, Schubert J, Junker K. P53 mutations as an identification marker for the clonal origin of bladder tumors and its recurrences. Oncol Rep 2003;10:2033-7.

[31] Höglund M. Bladder cancer, a two phased disease? Semin Cancer Biol. 2006 Feb 28; [Epub ahead of print]

[32] Tiery JP. Epithelial-mesenchymal transitions in tumour progression. Nat Rev Cancer 2002;2:442-454.

[33] Pardal R, Clarke MF, Morrison SJ. Applying the principles of stem-cell biology to cancer. Nat Rev Cancer 2003;3:895-902.

[34] Al-Hajj M, Becker MW, Wicha M, Weissman I, Clarke MF. Stem cells in normal breast development and breast cancer. Cell Prolif 2003;36 Suppl 1:59-72.

[35] Yuan X, Curtin J, Xiong Y, Liu G, Waschsmann-Hogiu S, Farkas DL, Black KL, Yu JS. Isolation of cancer stem cells from adult glioblastoma multiforme. Oncogene 2004;23:9392-9400. 
[36] Tsai YC, Simoneau AR, Spruck CH 3rd, Nichols PW, Steven K, Buckley JD, Jones PA. Mosaicism in human epithelium: macroscopic monoclonal patches cover the urothelium. $\mathrm{J}$ Urol 1995;153:1697-1700.

[37] Braakhuis BJ, Tabor MP, Kummer JA, Leemans CR, Brakenhoff RH. A genetic explanation of Slaughter's concept of field cancerization: evidence and clinical implications. Cancer Res 2003;63:1727-30.

[38] Dyrsjkot L, Kruhoffer M, Thykjaer T, Gene expression in the urinary bladder: a common carcinoma in situ gene expression signature exist disregarding histopathological classification. Cancer Res 2004;64:4040-4048

[39] Sanches-Carbayo M, Socci ND, Lozana J, Saint F, Cordon-Cardo C. Defining molecular profiles of poor outcome in patients with invasive bladder cancer using oligonucleotide microarrays. J Clin Oncol 2006;24:778-789

[40] Koss LG. Mapping of the urinary bladder: its impact on the concepts of bladder cancer. Hum Pathol 1979;10:533-48.

[41] Maley CC, Galipeau PC, Finley JC, Wongsurawat VJ, Li X, Sanchez CA, Paulson TG, Blount PL, Risques RA, Rabinovitch PS, Reid BJ. Genetic clonal diversity predicts progression to esophageal adenocarcinoma. Nat Genet 2006;38:468-73. 
Figure Legends

Figure 1. Schematic representation of the origin of clonally related tumors. Three urothelial carcinomas A, B, and C, showing the indicated mutated genes. Arrows indicates possible developmental routs from a common progenitor cell. Jagged arrow indicates a possible origin of tumor B from tumor A. Boxes contains two X chromosomes of which one is inactivated by methylation (gray shaded).

Figure 2. An outline of the field-first-tumor-later model. a) Normal urothelium organized in monoclonal patches as described by Tsai et al. [39], b) a first mutation occurs in a progenitor cell which daughter cells spread and occupy the monoclonal patch (indicated by light grey), c) cells in the first patch invade neighboring patches, d) in some patches further mutations occurs and the mutated cells spread into further neighbouring patches (indicated by grey), e) further mutations occurs (indicated by dark grey) and cells spreads to further neighboring patches and the urothelium eventually reaches a state of criticality, f) local critical genetic events results in the development of an overt tumor (indicated by a star), g) the same bladder after resection of the primary tumor in (f), h) a second critical genetic event occurs in a patch of modified cells that was present already when the primary tumor was resected. 


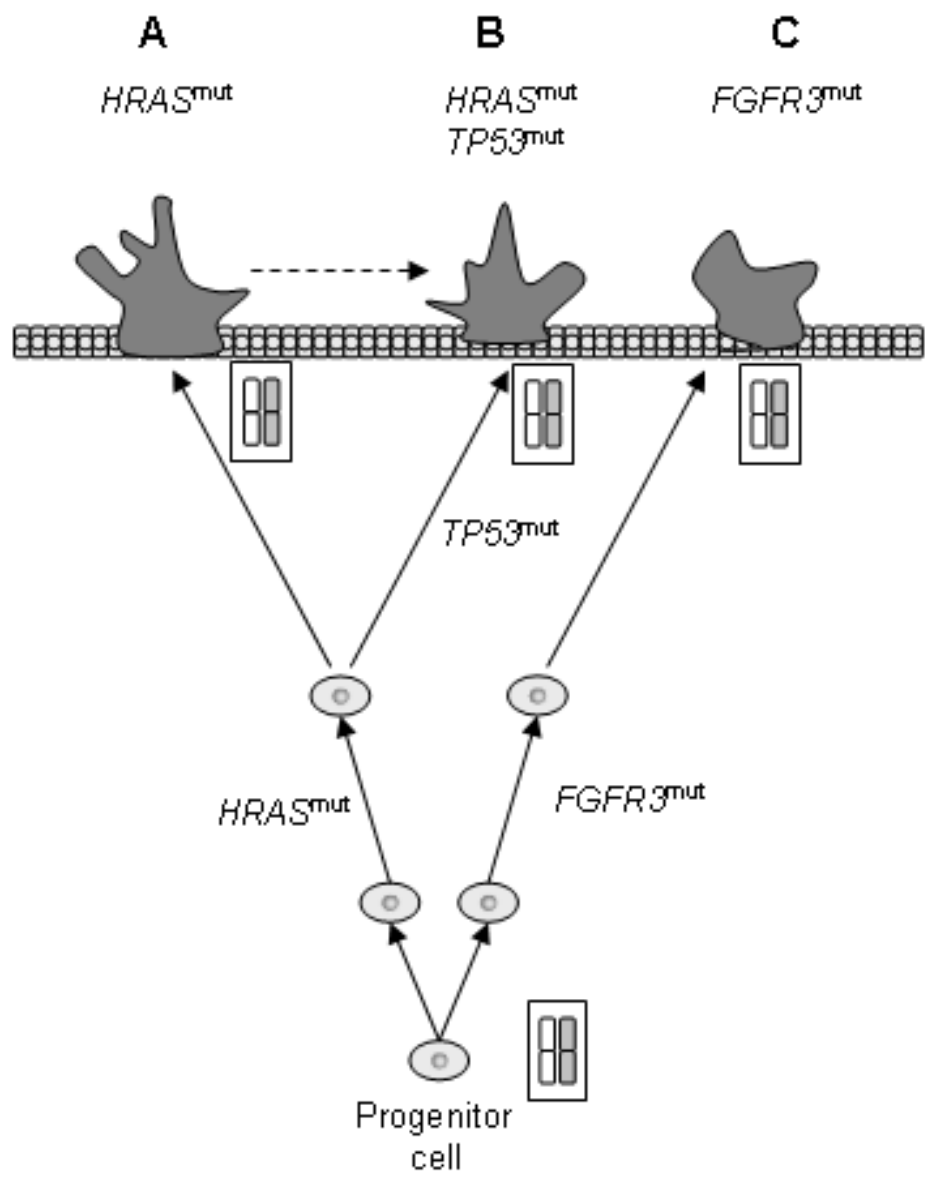




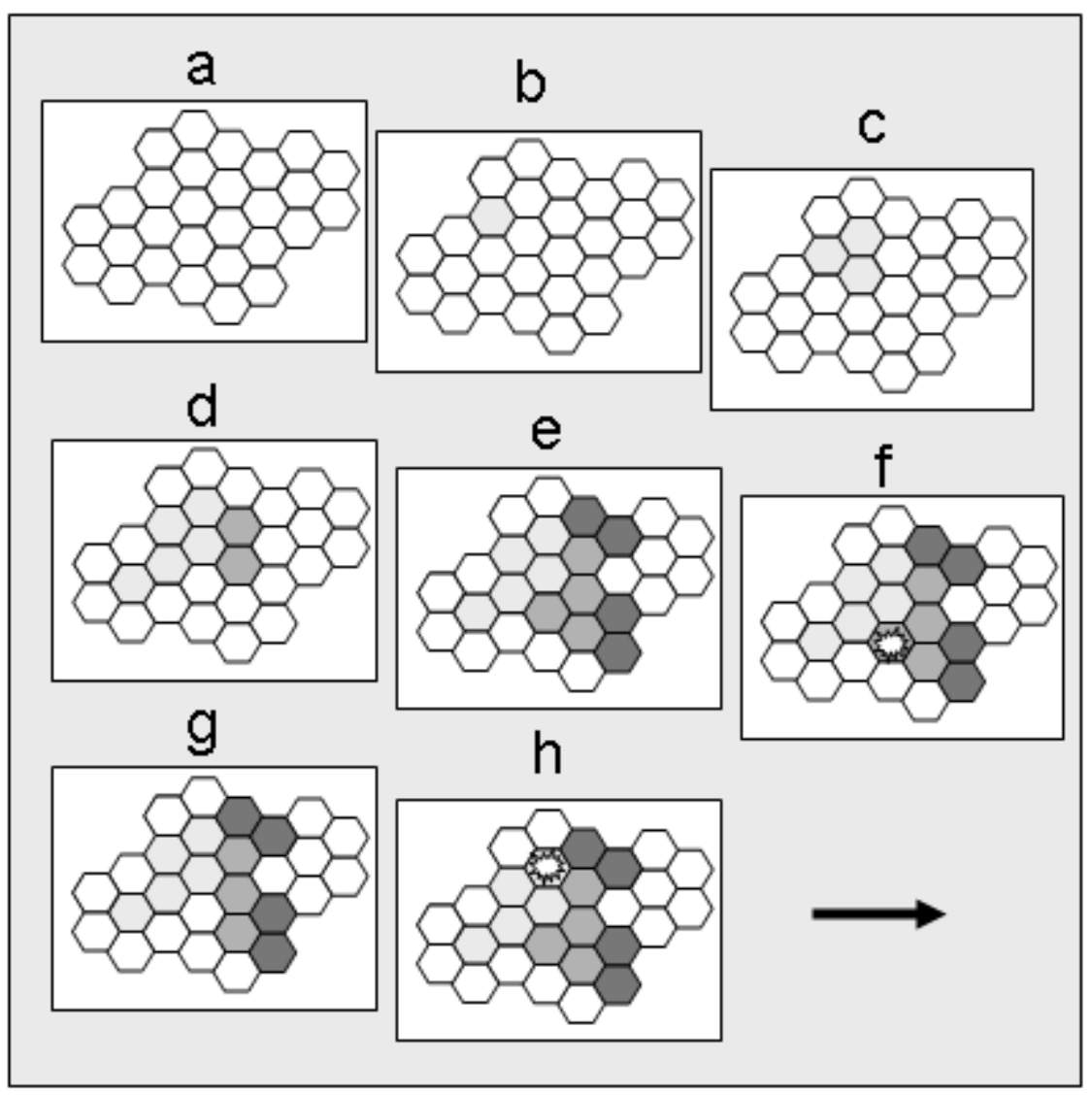

